\title{
Porto Alegre e Pelotas: duas experiências de municipalização do saneamento no Rio Grande do Sul da Primeira República.
}

\section{Porto Alegre and Pelotas: two experiences of municipalization of sanitation in the Rio Grande do Sul of the First Republic.}

Fabiano Quadros Rückert*

Felipe Maropo*

Resumo: O artigo aborda o processo de municipalização do saneamento em duas cidades do Rio Grande do Sul, no período da Primeira República (1889-1930). Explorando documentos do poder público, projetos de engenharia e matérias publicadas na imprensa da época, a pesquisa realizada destaca as estratégias jurídicas e financeiras usadas pelas duas municipalidades para interferir nos serviços de saneamento - abastecimento de água e coleta de esgoto - que estavam sob o controle de empresas particulares no começo da República. Dentro deste contexto, as discussões sobre salubridade urbana ganham importância e serão contempladas pelo artigo.

Palavras chaves: saneamento, municipalização, Porto Alegre, Pelotas, Primeira República.

\begin{abstract}
The article deals with the process of municipalization of sanitation in two cities of Rio Grande do Sul, during the period of the First Republic (1889-1930). Exploring public authority documents, engineering projects and materials published in the press of the time, the research carried out highlighted the legal and financial strategies used by the two municipalities to interfere in the services of sanitation water supply and sewage collection - that were under the control of private companies at the beginning of the Republic. Within this context, discussions on urban sanitation gain importance and will be addressed by the article.
\end{abstract}

Keywords: Sanitation, municipalization, Porto Alegre, Pelotas, First Republic.

\footnotetext{
${ }^{*}$ Doutor em Historia. Professor Adjunto na Universidade Federal do Mato Grosso do Sul - Campus do Pantanal. E-mail: fabianoqr@yahoo.com.br. Editor da Revista Brasileira de História \& Ciências Sociais.

${ }^{*}$ Mestre em História e Docente na Universidade Federal do Mato Grosso do Sul.
} 


\section{Revista Brasileira de História \& Ciências Sociais - RBHCS}

Vol. $9 \mathrm{~N}^{\mathrm{O}} 18$, Julho - Dezembro de 2017

\section{Introdução}

O tema da municipalização é frequentemente abordado a partir da perspectiva das Ciências Políticas, do Direito e da Sociologia. Na bibliografia referente ao assunto, predominam estudos que abordam a municipalização no período da República Nova, explorando o marco jurídico da Constituição Federal de 1988 e as negociações posteriormente acordadas entre as diferentes esferas do poder público - União, estados e municípios (ARRETCHE, 2000; SOUZA; FARIA, 2004). Essa bibliografia, apesar de oferecer elementos importantes para compreensão da dinâmica política brasileira e de fomentar discussões sobre a eficiência (ou ineficiência) do poder público, pouco nos diz sobre as práticas de municipalização ocorridas no Brasil em outras conjunturas políticas.

A priori, a municipalização pode ocorrer a partir de duas situações distintas: ela pode ser a transferência de atribuições da União Federal ou de um estado para os municípios; ou pode ser consequência de uma ação política que resulte no controle de um serviço público pela municipalidade. No primeiro caso, as negociações envolvem diferentes esferas do governo, e as mais recentes são interpretadas como parte da chamada descentralização administrativa implantada no Brasil a partir da Constituição de 1988. No segundo, as negociações envolvem a esfera municipal da administração pública e empresas particulares. Cabe ressaltar que esses dois tipos de municipalização não são excludentes e, apesar de distintos, produzem resultados semelhantes. Quando concluído, um processo de municipalização implica no aumento das responsabilidades jurídicas do município envolvido e pode gerar a necessidade de ampliação no quadro de funcionários públicos; por outro lado, o município pode controlar de forma mais efetiva o planejamento, os investimentos e os resultados obtidos no serviço que foi municipalizado. E, se existir uma taxa de cobrança específica - como ocorre no abastecimento de água e na coleta do lixo, o município envolvido passa a ser o administrador da receita gerada, podendo inclusive redefinir o valor ou a periodicidade da respectiva taxa.

A possibilidade de uma reflexão histórica sobre as práticas de municipalização no Brasil encontra alguns obstáculos, dentre os quais, podemos elencar a existência de uma tradição acadêmica que pensa a dinâmica política brasileira a partir da macroescala espacial. 


\section{Revista Brasileira de História \& Ciências Sociais - RBHCS}

Vol. $9 \mathrm{~N}^{\circ}$ 18, Julho - Dezembro de 2017

Na segunda metade do século XX, surgiu um conjunto expressivo de trabalhos que interpretam as relações sociais, a economia e as instituições políticas a partir da uma perspectiva nacional. Partindo de diferentes enfoques, obras como Formação do Brasil Contemporâneo (PRADO JÚNIOR, 1972), Os Donos do Poder (FAORO, 1989), O Minotauro Imperial (URICOCHEA, 1978) e Teatro de Sombras (CARVALHO, 1988), possuem em comum o interesse pela composição e funcionamento do aparelho estatal e ressaltam o papel do Estado no desenvolvimento econômico do Brasil.

Reduzindo a escala espacial da abordagem, identificamos outro conjunto de estudos que abordam experiências políticas de âmbito regional. Neste caso, predominam pesquisas que destacam as particularidades econômicas de determinadas regiões do Brasil, como por exemplo: o desenvolvimento da economia cafeeira e da indústria no Sudeste (SILVA, 1976; LAPA, 1986; CANO, 1990; COSTA, 1998) e a diversificação econômica provocada pela imigração na região Sul do Brasil (DACANAL; GONZAGA, 1980; SANTOS, 1999, ZARTH, 2002). O comportamento das elites regionais da Primeira República na condução dos assuntos econômicos e na negociação das divergências intraoligárquicas também recebeu uma expressiva atenção de historiadores brasileiros (FERREIRA, 1985; AXT; 2011; VISCARDI, 2012) e estrangeiros (LOVE, 1975; DEAN, 1976; PANG, 1979; LOVE, 1982; WIRTH, 1982).

Considerando a importância dos estudos de macroescala espacial na tradição acadêmica brasileira e a existência de um volume expressivo de pesquisas que abordam questões econômicas e políticas pelo viés regionalista, podemos inferir que o tema da municipalização - aqui entendido como o controle de um município sobre um determinado serviço público - é apenas uma "nota de rodapé" na bibliografia que aborda a história política e a histórica econômica do Brasil. Contudo, essa "nota de rodapé” existe e demanda a nossa atenção.

$\mathrm{Na}$ sequência do artigo apresentamos uma pesquisa focada na história da municipalização dos serviços de saneamento no Rio Grande do Sul da Primeira República (1889-1930). Uma parte dessa história diz respeito à municipalização das antigas Companhias Hidráulicas criadas no Império para explorar comercialmente o abastecimento de água nas cidades de Pelotas e Porto Alegre. Outra parte diz respeito à municipalização das empresas de Serviço de Asseio Público que, na transição do 


\section{Revista Brasileira de História \& Ciências Sociais - RBHCS}

Vol. $9 \mathrm{~N}^{\mathrm{O}} 18$, Julho - Dezembro de 2017

século XIX para o XX, realizavam a remoção e a limpeza periódica dos cubos com "materias fecaes" nas respectivas cidades.

\section{Os primórdios do saneamento no Rio Grande do Sul Imperial}

Dentro do modelo político imperial, a responsabilidade pela salubridade urbana era dos municípios e das províncias e, consequentemente, as iniciativas para tornar as cidades mais higiênicas e para prover as populações de água potável deveriam partir das Câmaras Municipais e dos governos provinciais. Implantado pela Constituição de 1824 e aprimorado por outros dispositivos jurídicos, como o Regulamento das Câmaras Municipais do Império, de 1828, o modelo político imperial apresentou problema de operacionalidade, dentre os quais importa destacar (1) a insuficiência dos recursos municipais e provinciais para atender as responsabilidades atribuídas pela legislação; e (2) as limitações no quadro de funcionários do poder público, sobretudo em áreas como a Medicina e a Engenharia. $\mathrm{Na}$ prática, poucos municípios tinham condições financeiras e recursos humanos para atacar os problemas que comprometiam a salubridade da população no Brasil Imperial e os governos provinciais também enfrentavam dificuldades financeiras.

Foi dentro deste contexto que a concessão da exploração de serviços de interesse público para empresas particulares tornou-se comum no Império. Serviços como o abatimento de reses e o comércio de carne verde, o calçamento de ruas, a perfuração de poços e cacimbas, a construção de pontes e a edificação de prédios para administração pública eram viabilizados através de negociações entre as autoridades imperiais e particulares que submetiam suas propostas pleiteando os contratos de concessão.

$\mathrm{Na}$ área do saneamento, as concessões para a realização do Asseio Público eram feitas pelas Câmaras Municipais, mediante a concordância prévia do governo provincial. Em troca dos investimentos necessários para execução do serviço, o concessionário recebia o direito de cobrar pela remoção e limpeza dos cubos, desde que respeitando os valores indicados pelas municipalidades.

No que diz respeito ao serviço de abastecimento de água, as concessões apresentavam certas particularidades. O plano de obras deveria ser submetido à apreciação do governo provincial; este, por sua vez, determinava o volume mínimo de água que deveria ser fornecido, a quantidade de chafarizes que deveriam ser 


\section{Revista Brasileira de História \& Ciências Sociais - RBHCS}

Vol. $9 \mathrm{~N}^{\mathrm{O}}$ 18, Julho - Dezembro de 2017

instalados e o preço para comercialização da água. O custo das obras era responsabilidade das Companhias Hidráulicas que deveriam apresentar ao governo estatutos descrevendo as diretrizes gerais da sua composição e funcionamento. A contrapartida do governo para compensar o investimento dos acionistas, era a garantia do privilégio na exploração do serviço por um determinado período, além do pagamento de juros sob o capital aplicado, até que a receita superasse as despesas contraídas na fase de implantação do serviço.

Como consequência da política imperial de concessão dos serviços de saneamento, quando a República foi Proclamada, as cidades de Pelotas e Porto Alegre já possuíam sistemas de abastecimento de água e empresas realizando o Asseio Público. $^{1} \mathrm{Na}$ capital do Rio Grande do Sul, duas empresas exploravam a comercialização da água: a Companhia Hydráulica Porto-Alegrense (criada em 1861) e a Companhia Hydráulica Guahybense (criada em 1885); e o serviço de coleta e descarte de cubos com "materias fecaes" era feito por uma empresa particular, mediante concessão negociada com a municipalidade. Na cidade de Pelotas, Companhia Hydráulica Pelotense foi criada em 1871 e iniciou o fornecimento nos chafarizes e penas em 1875. Nessa mesma época, Pelotas também possuía um serviço de Asseio Público que atendia o perímetro central da cidade.

A implantação do Asseio Público em Porto Alegre foi um dos temas pesquisados por Vladimir Ferreira de Ávila. Com base no trabalho deste autor, sabemos que o problema da coleta e descarte das "materias fecaes" ganhou importância na pauta da Câmara de Porto Alegre na década de 1850. Inicialmente, a Câmara procurou interferir na prática dos despejos fecais através das Posturas Municipais e definiu os locais e horários para a respectiva prática. Um segundo tipo de interferência ocorreu em 1872 quando a municipalidade firmou contrato com Estácio da Cunha Betencourt, criador da Empresa Salubridade Pública (ÁVILA, 2010, p. 140). A partir deste ano, os prédios localizados no perímetro urbano de Porto Alegre podiam contratar o serviço de remoção das latrinas - também chamadas de cubos ou cabungos - de acordo com as condições fixadas no contrato de concessão. A adesão ao Asseio Público era facultativa e, consequentemente, muitos proprietários

\footnotetext{
${ }^{1}$ A cidade portuária do Rio Grande também possuía os respectivos serviços de saneamento; no entanto, ela não está contemplada neste artigo.
} 


\section{Revista Brasileira de História \& Ciências Sociais - RBHCS}

Vol. $9 \mathrm{~N}^{\mathrm{O}}$ 18, Julho - Dezembro de 2017

optaram por continuar com as antigas práticas de descarte das matérias fecais, dentre as quais estavam o despejo em vias públicas, nos quintais ou em terrenos baldios.

Desde a sua implantação, o Serviço de Asseio Público em Porto Alegre foi alvo de reclamações, algumas publicadas na imprensa, outras dirigidas à Câmara Municipal. No curto período em que foi realizado pela Empresa Salubridade Pública (1872-1875), o Asseio Público foi alvo de reclamações procedentes de diversas partes: alguns moradores reclamavam da irregularidade do serviço, Betencourt reclamava da falta de colaboração dos usuários, outros reclamavam de despejos "ilegais" realizados pelos quartéis da cidade, a Câmara reclamava da ineficiência da Empresa Salubridade Pública na remoção dos cubos, e o Inspetor de Higiene da Província reclamava de todos. Reagindo ao quadro de insatisfação coletiva, a municipalidade submeteu o contrato de Betencourt a uma revisão judicial e revogou a concessão, no dia 20 de outubro de 1875 .

Na década final do Império o Asseio Público continuou produzindo polêmicas na sociedade porto-alegrense. Naquele contexto, cresceu a preocupação com a higiene pública e discutiu-se a possibilidade de tornar obrigatória a adesão ao serviço. A necessidade de afastar os despejos do núcleo urbano de Porto Alegre para evitar o risco de transmissão de doenças também foi discutida na imprensa, mas nem uma medida efetiva foi encaminhada antes da Proclamação da República.

A pesquisa realizada por Rückert (2015) sobre abastecimento de água na Porto Alegre Imperial apresenta um panorama geral do processo de instalação das empresas concessionárias do serviço na capital sul rio-grandense. Um aspecto relevante apontado pelo autor é a mudança na posição da sociedade porto-alegrense a respeito das águas do Guaíba: na década de 1850 esse manancial foi considerado impróprio para consumo e por isso a Companhia Hydráulica Porto-Alegrense investiu na captação das águas nas nascentes do Arroio do Sabão (atualmente chamado de Arroio Dilúvio); posteriormente, na década de 1880 a opção pela captação no Guaíba foi repensada e a Companhia Hydráulica Guahybense recebeu autorização para explorar este manancial, sob a condição que instalasse um sistema para purificação das águas. Desta forma, Porto Alegre encerrou o período imperial com duas empresas comercializando águas de procedência distintas.

O desenvolvimento dos serviços de saneamento na Porto Alegre imperial apresentou semelhanças com o que ocorreu na cidade de Pelotas - principal núcleo 


\section{Revista Brasileira de História \& Ciências Sociais - RBHCS}

Vol. $9 \mathrm{~N}^{\mathrm{O}} 18$, Julho - Dezembro de 2017

da produção do charque na província. ${ }^{2}$ Durante a formação de Pelotas, a precoce concentração de charqueadas nas margens do Canal São Gonçalo, do Arroio Pelotas e do Arroio Santa Bárbara, assim como o uso destes mananciais para descarte dos resíduos gerados pela indústria saladeril, influenciaram na gradual expansão do sítio urbano em direção ao sul. O planejamento desta expansão foi conduzido pela Câmara Municipal que em 1832 ordenou a construção de cacimbas na Rua Nova das Fontes (MAGALHÃES, 2011, p. 60-61). Posteriormente, na intenção de ampliar a oferta de água, em 1835 a Câmara Municipal desapropriou um poço particular para torná-lo de uso público e concedeu uma indenização ao proprietário (SILVEIRA, 2009, p. 42).

A preocupação com o abastecimento de água foi registrada em diversas ocasiões nas Atas da Câmara Municipal referentes às décadas de 1830 e 1840. Havia uma demanda por água potável e para atendê-la, em 1851 a municipalidade providenciou a construção de uma cisterna no subsolo do Mercado Público. A obra foi construída com o auxílio de um empréstimo obtido junto ao governo provincial. Ela armazenava a água da chuva que era distribuída gratuitamente para a população e "tinha capacidade para prover diariamente 900 pipas de água. (XAVIER, 2010, p. $56) "$

A construção da cisterna foi seguida de outras iniciativas do poder público voltadas para ampliar a oferta de água em Pelotas. Em 1861 o governo provincial contratou o engenheiro italiano Ângelo Cassapi para fazer perfurações e captar água do lençol freático, mas os resultados encontrados não foram satisfatórios. Ainda na década de 1860, a Província emitiu parecer favorável para o projeto de abastecimento de água apresentado pelo francês Jules Villain; no entanto, as obras previstas não foram executadas por desistência do autor (WEIMER, 1998, p. 98). Em 1869, o comerciante pelotense Domingos Rodrigues Cordeiro e o engenheiro inglês John Storry iniciaram negociações para concessão do serviço e, posteriormente, desistiram do investimento alegando impossibilidade de cumprir as exigências contratuais fixadas pela Província.

\footnotetext{
${ }^{2}$ A importância do charque para o desenvolvimento de Pelotas foi detalhadamente pesquisada pelo historiador Jonas Moreira Vargas (VARGAS, 2013). O autor abordou as redes comerciais que ligavam os charqueadores de Pelotas aos estancieiros do Uruguai e da Campanha sul rio-grandense e, ao mesmo tempo, possibilitavam a exportação do charque pelotense para o centro do Império. Outro importante trabalho para compreensão do funcionamento da economia saladeril em Pelotas, é a obra de Jorge Euzébio Assumpção (ASSUMPÇÃO, 2013); nesta, o autor revisou a bibliografia sobre o trabalho escravo nas charqueadas e a partir de uma ampla fonte documental, analisou varáveis como gênero, procedência, expectativa de vida e idade dos cativos.
} 


\section{Revista Brasileira de História \& Ciências Sociais - RBHCS}

Vol. $9 \mathrm{~N}^{\circ} 18$, Julho - Dezembro de 2017

As negociações entre a Província e os investidores interessados em explorar o abastecimento de água em Pelotas avançaram quando em 1871 o português Hygino Corrêa Durão, e o seu sócio João Frick, apresentaram um plano de obras e receberam autorização do governo para executá-lo. O plano previa um sistema de captação e distribuição composto das seguintes partes: (1) uma represa no Arroio Moreira, no local da captação; (2) um depósito de clarificação com capacidade para três mil litros cúbicos, podendo este depósito ser subdivido em vários tanques; (3) a construção de uma adutora com canos de ferro fundido ligando o ponto da captação ao centro da cidade, sendo a dimensão dos canos calculada para abastecer uma população de doze a quatorze mil habitantes; (4) um grande reservatório metálico para regularizar o fluxo de água; (5) e a instalação de quatro chafarizes em locais que seriam determinados pela Câmara Municipal (Indicações que acompanham as plantas das Empresas Hydráulicas do Rio Grande e Pelotas apresentadas pelos concessionários Hygino Corrêa Durão e João Frick. o9 de dezembro de 1871. Caixa 15, Maço 31, AHRS).

Depois de obter do governo a concessão para realizar as obras e explorar o serviço de abastecimento de água em Pelotas, Higyno Corrêa Durão transferiu os direitos adquiridos para o grupo de investidores que organizou a Companhia Hydráulica Pelotense; neste grupo, estavam importantes membros da sociedade local.3 Contando com a participação de engenheiros europeus, com o capital de membros da elite pelotense e com tecnologias importadas da Europa, a Companhia inaugurou o serviço de abastecimento de água em Pelotas, no dia 05 de abril de 1875.

A instalação dos chafarizes feita pela Companhia Hydráulica Pelotense e o fornecimento de água encanada para as propriedades que contratavam o arrendamento de penas, foram marcos importantes na história da urbanização em Pelotas (SILVEIRA, 2009; XAVIER, 2010). Sob a influência das obras de saneamento realizadas nas grandes cidades europeias da época, a elite pelotense desejava tornar a cidade higiênica. E, para atingir esse objetivo, ela providenciou diversas ações de

\footnotetext{
3 A primeira Diretoria da Companhia Hydráulica Pelotense foi composta por "João Simões Lopes (Visconde da Graça), Antônio José de Azevedo Machado Filho (filho do Barão de Azevedo Machado) e Felisberto Ignácio da Cunha (Barão de Correntes)" (SILVEIRA, 2009, p. 152). Cabe ressaltar que a responsabilidade pela execução das obras aprovadas pelo governo continuou sendo do engenheiro Hygino Corrêa Durão e que ele acompanhou, através dos seus representantes, o andamento dos trabalhos contratos com a Província.
} 


\section{Revista Brasileira de História \& Ciências Sociais - RBHCS}

Vol. $9 \mathrm{~N}^{\mathrm{O}}$ 18, Julho - Dezembro de 2017

cunho sanitário, dentre as quais estavam a implantação de um serviço para coleta e descarte das "materias fecaes" geradas pela sociedade pelotense (SOARES; 2002).

Na pesquisa realizada, não localizamos informações sobre a implantação do Asseio Público em Pelotas. Certamente o serviço foi implantado antes de 1875, pois neste ano, o Jornal Correio Mercantil publicou uma matéria afirmando que apesar da existência duas empresas realizando a coleta de matérias fecais, muitos moradores estavam transformando "os seus quintaes em latrinas", cavando "buracos pouco profundos" para descartar os despejos das suas casas (Correio Mercantil. o5 de março de 1875. BNRJ-HD).

Assim como ocorreu em Porto Alegre, na Pelotas imperial surgiram discussões sobre a eficiência do Asseio Público. Nas páginas da imprensa, encontramos diversas críticas ao respectivo serviço e também textos denunciando a prática dos despejos de matérias fecais em quintais, terrenos baldios e vias públicas.

A precariedade do Asseio Público e a resistência dos moradores em aderir ao respectivo serviço provocavam a preocupação das autoridades pelotenses. Qualificar o Asseio Público e impor a sua obrigatoriedade para todos os imóveis do perímetro urbano foram opções discutidas. No entanto, prevaleceu a ideia de construção da rede de esgoto para Pelotas. Desta forma, em 1887 a Câmara Municipal anunciou sua disposição para estudar projetos de saneamento que deveriam ser submetidos à apreciação de uma Comissão composta por engenheiros, médicos e autoridades públicas indicadas pelos vereadores. O projeto escolhido foi o do engenheiro francês Gregorio Howyan.

Depois de ser submetido à apreciação da municipalidade, o projeto de Howyan foi encaminhado para apreciação do governo provincial. Na Assembleia da Província, ele foi obejeto de discussões entre os deputados que consideravam juridicamente correto o procedimento da Câmara de Pelotas e os que discordavam, sob a alegação de que as decisões referentes ao abastecimento de água eram responsabilidade da Província. Ao término das discussões, o projeto de obras de Howyan foi aprovado pela Assembleia Provincial do Rio Grande do Sul - a mesma Assembleia que foi destituída com a Proclamação da República.4

4 Cabe ressaltar que em 1888, antes de ser aprovado pela Assembleia Provincial, o Projeto de Gregorio Howyan recebeu críticas do então Vice-Presidente, o Barão de Santa Tecla. Apesar das críticas registradas no Relatório Provincial de 1888, em abril de 1889 o Dr. Joaquim Galdino Pimentel, na 


\section{A municipalização do saneamento na capital do Rio Grande do Sul}

O primeiro serviço de saneamento municipalizado em Porto Alegre foi o Asseio Público, cujo funcionamento estava diretamente relacionado à necessidade de proteção da salubridade urbana. Como demonstram os estudos de autores como Corbin (1987) e Rosen (2000) e Larrea-Killinger (1997), dentre outros, o interesse dos médicos pela salubridade urbana e pelas questões referentes à higiene pública foi intensificado no decorrer do século XIX, período marcado por grandes epidemias, sobretudo as cólera e febre amarela. Naquele contexto, a teoria dos miasmas ainda exercia grande influência sobre o pensamento médico e, consequentemente, a identificação e o combate dos focos de decomposição de matérias orgânicas, assim como os cuidados com a circulação do ar, ganharam importância na agenda médica.

Em Porto Alegre, o surgimento de uma preocupação médica com o destino das "materias fecaes" foi abordado por autores como Ávila (2010), Huyer (2015) e Rückert (2015 e 2016b). Os autores afirmam que essa preocupação já estava configurada nas décadas finais do Império, quando foi discutida por membros da comunidade médica porto-alegrense. Posteriormente, em 1893, a Intendência recorreu ao saber médico para solucionar o problema das "materias fecaes". A solução apontada pela comissão de profissionais da medicina que estudou o assunto foi a construção de uma ferrovia para afastar os despejos do Asseio Público do núcleo urbano da cidade.

Acatando a sugestão, a municipalidade empenhou-se na construção da ferrovia que deveria ligar o centro da cidade ao local conhecido como Ponta do Dionísio. Neste mesmo ano, a Intendência passou a exigir a adesão dos proprietários de imóveis ao serviço de Asseio Público através de intimações emitidas pela Seção de Higiene e publicadas na imprensa.5

condição de Presidente da Província, aprovou o contrato entre a Câmara Municipal de Pelotas e o engenheiro Gregorio Howyan.

5 Uma nota de 15 de abril de 1893 informava aos leitores sobre os procedimentos tomados pela Intendência: "No intuito de fazer cessar o prejudicial abuso dos despejos de materias fecaes nas calhas das ruas, bem como seu enterramento nos quintaes, o cidadão intendente municipal mandou verificar quaes os prédios cujos moradores não tem o competente cubo, indispensável ao serviço de asseio, além de serem estes intimados a adquiri-los em curto prazo, a bem da saúde pública. Diariamente, aparecerá no expediente da intendência, a relação dos intimados para tal fim.” A Federação. Asseio da Cidade. 15 de abril de 1893, p. 2. (BNRJ-HD) 


\section{Revista Brasileira de História \& Ciências Sociais - RBHCS}

Vol. $9 \mathrm{~N}^{\mathrm{O}}$ 18, Julho - Dezembro de 2017

A construção da linha férrea - chamada na época de Ferrovia do Riacho demandou um grande investimento financeiro da municipalidade e foi dificultada por problemas técnicos e por questões jurídicas (HUYER, 2015). Por objeção do proprietário das terras da Ponta do Dionísio, o traçado da ferrovia foi modificado e direcionado para a Ponta do Melo, local que também atendia a preocupação médica de afastar os despejos fecais do centro da capital. Superando diferentes tipos de adversidade, a obra avançou e criou as condições necessárias para a Intendência realizar uma importante intervenção no saneamento de Porto Alegre: a encampação do Asseio Público, fato ocorrido em 1898.

No findar do século XIX, o Asseio Público de Porto Alegre estava sob o controle da municipalidade que determinou a adesão obrigatória ao serviço para todos os imóveis do perímetro urbano. Criou-se assim uma conjuntura financeiramente favorável para a rápida expansão e qualificação do serviço de coleta e descarte dos cubos com "materias fecaes."

Em linhas gerais, estes foram os fatos que marcaram a municipalização do Asseio Público em Porto Alegre. Cabe acrescentar que a construção da Ferrovia do Riacho e a encampação do Asseio Público foram intervenções no saneamento da cidade, pois o objetivo principal da Intendência era a construção de uma rede coletora de esgoto - obra que foi realizada entre 1905 e 1912. Dito isso, podemos concentrar nossa atenção no processo de municipalização do abastecimento de água em Porto Alegre.

Nos anos que antecederam o fim do Império, a imprensa da capital sul riograndense publicou diversas matérias criticando irregularidades no fornecimento de água realizado pela Companhia Hydráulica Porto-Alegrense. A iniciativa da empresa de instalar hidrômetros para coibir o excesso de consumo também suscitou reclamações dos usuários. A insatisfação com o serviço e a expectativa dos usuários de um posicionamento do governo a respeito do assunto motivaram a criação de uma Comissão para avaliar as condições do sistema de abastecimento da empresa, fato ocorrido em $1895{ }^{6}$

A Comissão foi composta pelos engenheiros José Montaury de Aguiar Leitão, José da Costa Gama e João Cancio Ferreira da Silva. Ela inspecionou os reservatórios

\footnotetext{
${ }^{6}$ A Federação. Companhia Hydraulica Porto-Alegrense, 02 de janeiro de 1895, p. 2. - A Federação. Falta d'agua, og de janeiro de 1895, p.2. (BNRJ-HD)
} 


\section{Revista Brasileira de História \& Ciências Sociais - RBHCS}

Vol. $9 \mathrm{~N}^{\mathrm{O}}$ 18, Julho - Dezembro de 2017

da empresa e analisou documentos que indicavam uma disparidade no consumo da água entre as penas com hidrômetro e as que não estavam sujeitas ao aparelho de medição. A Comissão reconheceu que o uso dos hidrômetros era uma alternativa para "evitar os esbanjamentos" e afirmou que o volume de água fornecido pelos reservatórios da Companhia, apesar de atender as obrigações previstas pelo contrato - 500 litros diários por pena - era insuficiente para a demanda da cidade, sobretudo nos meses de verão.7 Diante do problema da disparidade no consumo, da insuficiência no volume distribuído e da proximidade de encerramento do contrato entre a Companhia Hydraulica Porto-Alegrense e o governo, foram apresentadas as seguintes sugestões:

É de parecer da commissão que o governo do Estado procure os meios que julgar mais convenientes para facilitar á companhia o emprego do hydrometro sem augmentar o número de pennas, e tratar opportunamente de mandar proceder aos necessários estudos para um plano de augmento d'agua á população, tornando obrigatório o emprego e fornecimento dos hydrometros a todos os prédios dentro da circunscrição urbana.

Nos estudos que se tenha de mandar proceder deve-se ter em vista o abastecimento d'agua ás classes desfavorecidas de fortuna, cuja falta no estio rigoroso compromette a salubridade geral, e é attendendo a essa circunstância que muitos auctores que se tem occupado de estudos de abastecimento d'agua ás cidades, são de opinião, por nós compartilhada, que seja ele feito pelos poderes públicos, cuja responsabilidade pelo interesse geral não se mede pelo que possam toma capitaes de acionistas de emprezas ou companhias ( $A$ Federação. Parecer, 21 de maio de 1895, p. 1-2. BNRJ-HD).

A posição da Comissão a respeito do abastecimento de água em Porto Alegre refeletia a concepção de serviço público compartilhada pelo Partido Republicano RioGrandense (PRR) - grupo político que assumiu o governo do Rio Grande do Sul na ocasião da Proclamação da República. ${ }^{8}$ Os líderes do PRR entendiam que os serviços

\footnotetext{
7 O cálculo usado pela Comissão para avaliar a déficit diário no abastecimento foi o seguinte: "A população de Porto Alegre calculada em 64 mil habitantes e considerando-se 8 em cada casa, a média é de 63 litros por habitantes. Todos quantos tem escripto sobre abastecimento d'agua fixam como mínimo 100 litros e como média 150 por habitante e para países cujas latitudes são muito mais elevadas do que as dessa capital. [...]. A commisão pensa que em uma cidade importante, onde a população urbana cresce diariamente, como se vê n'esta capital, deve-se procurar os meios de bem abastecê-la d'agua, fixando-se cada penna ao mínimo em 1000 litros ou 125 por habitantes.” $A$ Federação. Parecer - Conclusão, 21 de maio de 1895, p. 2. (BNRJ-HD) A parte inicial do documento produzido pela Comissão foi publicada na edição do dia anterior com o título de "Parecer".

8 Existem diversos estudos que abordam as ideias e práticas do Partido Republicano Rio-Grandense. Revisando a bibliografia sobre este assunto, Gunter Axt (2011) identificou duas correntes de interpretação: a primeira explora a capacidade do PRR construir alianças com os setores mais dinâmicos da economia sul rio-grandense da época, formando "uma homogeneidade de interesses" articulados em torno de um projeto de modernização econômica e social; a segunda valoriza a
} 


\section{Revista Brasileira de História \& Ciências Sociais - RBHCS}

Vol. $9 \mathrm{~N}^{\mathrm{O}}$ 18, Julho - Dezembro de 2017

de interesse público deveriam estar sob o controle do governo e, seguindo este entendimento, encaminharam procedimentos para interferir no "negócio das águas" que estava em curso na capital do Rio Grande do Sul.

A primeira iniciativa para municipalizar o abastecimento de água em Porto Alegre ocorreu em 1902 quando a Intendência inquiriu as duas empresas sob a possibilidade de um acordo para viabilizar a encampação. Nesta ocasião, as duas companhias expressaram objeção à ideia de um acordo com a municipalidade. Sem a perspectiva da encampação, a Intendência solicitou que a Comissão Municipal de Saneamento apresenta-se orçamentos para a criação de uma rede de abastecimento de água com máquinas e encanamentos novos. A Comissão apresentou cálculos demonstrando que o governo poderia construir uma nova rede de distribuição com um valor semelhante ao que estava sendo pedido pelas companhias hidráulicas, obtendo ainda a vantagem na durabilidade do material.

A questão da encampação, apesar de desejada pela municipalidade, permaneceu indefinida até 1904, quando a Companhia Hydraulica Guahybense apresentou uma oferta para aquisição do seu patrimônio que foi considerada "justa" pela Intendência. No dia 01 de outubro de 1904, a municipalidade assinou a encampação da empresa pelo valor de 423:000\$000.9 Com essa iniciativa, a Intendência assegurou o controle sobre a captação das águas do Guaíba e pode encaminhar o plano de obras proposto pela Comissão Municipal de Saneamento, desistindo da encampação das duas empresas.

Cabe ressaltar que a municipalização do abastecimento de água em Porto Alegre não impediu que a Companhia Hydraulica Porto-Alegrense continuasse abastecendo uma parte da cidade com águas captadas nas nascentes do atual Arroio Dilúvio. Isso foi possível porque o sistema de captação e a rede de distribuição da empresa não dependiam das águas do Guaíba.

existência de conflitos no interior do bloco partidário; problematiza os motivos do intervencionismo estatal na economia e contempla as múltiplas estratégias do PRR para assegurar a viabilidade do governo. Como pontos em comum entre as duas correntes de interpretação, Axt destaca a ênfase na expansão e fortalecimento do aparelho estatal e a valorização do positivismo como explicação para o "mito" da eficiência administrativa do Partido Republicano Rio-Grandense.

9 Inicialmente, a Companhia Hydraulica Guahybense havia pedido uma indenização de 638:042\$500, valor que incluía "lucros cessantes durante o resto da concessão". Relatório apresentado pelo intendente José Montaury de Aguiar Leitão ao Conselho Municipal na sessão ordinária de 1907. In: A Federação. 23 de nov. de 1907. (BNRJ-HD) 
Revista Brasileira de História \& Ciências Sociais - RBHCS

Vol. $9 \mathrm{~N}^{\mathrm{O}}$ 18, Julho - Dezembro de 2017

\section{A municipalização do saneamento em Pelotas}

Pelotas iniciou a República contando com uma população de aproximadamente 41.591, segundo o Censo realizado em 1890 (FEE, 1981, p. 94). No perímetro urbano da cidade, o regime republicano defrontou-se com problemas que já estavam configurados no Império, dentre os quais estavam a insuficiência no abastecimento de água, ${ }^{10}$ a precariedade no serviço de Asseio Público, as limitações orçamentárias para a construção da rede de esgoto; os altos índices de doenças e mortalidade e uma demanda por investimentos públicos nas áreas da saúde, habitação, educação e transporte (GUTIERRES, 1999; GILL, 2005).11

No começo da República, o Asseio Público de Pelotas era realizado por uma empresa autorizada pela municipalidade, sendo um serviço restrito ao perímetro urbano e de adesão opcional. Em 1890, existiam 4.200 prédios em Pelotas, destes, apenas 1.000 usavam o Asseio Público. ${ }^{12} \mathrm{O}$ funcionamento do serviço apresentava deficiências e constantemente recebia críticas da imprensa pelotense. Consultando a posição dos jornais sobre a remoção e descarte dos cubos com "materias fecaes", observamos uma interessante divergência entre o que era considerado prioritário para o saneamento da cidade: alguns textos publicados na imprensa cobravam uma intervenção da municipalidade para qualificar o Asseio Público; outros, afirmavam que a prioridade era a construção da rede de esgoto.

A divergência registrada nos jornais de Pelotas também se manifestou nas ações da municipalidade. Inicialmente, a Intendência investiu na construção no projeto de saneamento elaborado por Howyan e aprovado pela extinta Assembleia Provincial. No entanto, a execução do respectivo projeto foi considerada tecnicamente inviável pela empresa contratada. Diante do fracasso dessa iniciativa e da necessidade de novos estudos técnicos e de investimentos financeiros elevados para a construção da rede de esgoto, a municipalidade decidiu encampar a Empreza Asseio Pelotense, na intenção de qualificar e expandir o serviço de remoção e descarte dos cubos com "materias fecaes".

\footnotetext{
10 Opinião Pública. 31 de agosto de 1890. Diário Popular. o1 de abril de 1894. (BPP)

${ }^{11}$ Os estudos que abordam o período inicial da República em Pelotas, apontam para o agravamento dos problemas de infraestrutura urbano e para as precárias condições de vida enfrentadas pela incipiente classe operária pelotense. Convém lembrarmos que as charqueadas usavam numerosa mão de obra escrava e que elas entraram em declínio na transição do século XIX para o XX - período em que uma parte da população empregada nas charqueadas deslocou-se para o núcleo urbano, em busca de oportunidades de trabalho.

${ }_{12}$ Correio Mercantil. 12 de julho de 189o. (BPP)
} 


\section{Revista Brasileira de História \& Ciências Sociais - RBHCS}

Vol. $9 \mathrm{~N}^{\mathrm{O}}$ 18, Julho - Dezembro de 2017

O segundo movimento da Intendência, após a encampação, foi instituir a obrigatoriedade da adesão ao Asseio Público. E, para assegurar a viabilidade financeira do serviço, ela incluiu na Lei de Orçamento de 1904 uma tabela com as novas taxas que seriam cobradas pela remoção dos cubos. Neste mesmo ano, a Intendência transferiu as instalações do Asseio Público para a antiga Xarqueada Valladares, nas margens do Canal São Gonçalo, e providenciou a compra de mil cubos metálicos para substituir os velhos cubos de madeira. ${ }^{13}$

A encampação do Asseio Público, a criação de novas taxas e os investimentos realizados pela municipalidade para qualificar e expandir o serviço foram temas noticiados e discutidos pela imprensa pelotense. Pesquisando este tema nos jornais Correio Mercantil, Opinião Pública e Diário Popular, constatamos que não havia um consenso na imprensa pelotense a respeito do Asseio Público. ${ }^{14}$ No entanto, a preocupação com as condições sanitárias da cidade e a expectativa da construção da rede de esgoto eram pontos consensuais.

Ao mesmo tempo em que absorvia novas responsabilidades decorrentes da encampação do Asseio Público, a Intendência estava empenhada no estudo de alternativas para ampliar a oferta de água. A ampliação no volume de água disponível para a população era justificada por dois motivos: de um lado, havia uma demanda que não era atendida satisfatoriamente pela Companhia Hydráulica Pelotense - fato registrado em dezenas de matéria publicadas na imprensa local; e, do outro, havia a necessidade de maior oferta para assegurar a limpeza da rede de esgotos que estava nos planos da municipalidade e era reivindicada por determinados setores da sociedade pelotense.

Os documentos consultados por Janaína Silva Xavier, na sua pesquisa sobre o patrimônio histórico do saneamento em Pelotas, indicam que, inicialmente, a municipalidade estudou a viabilidade de promover investimentos públicos no saneamento sem interferir nos trabalhos da Companhia Hydráulica Pelotense (XAVIER, 2010). Mas a deterioração das relações entre a Intendência e a empresa, sobretudo no período entre 1906 e 1908, tornaram essa possibilidade inviável.

\footnotetext{
13 Diário Popular. 22 de junho de 1904. (BPP)

14 Apesar da ausência de um consenso na imprensa pelotense a respeito da encampação do Asseio Público, a iniciativa produziu resultados positivos. Segundo Soares (2002, p.96), entre 1904 e 1909, o número de imóveis atendidos pelo Asseio Público passou de 2.106 para 3.390.
} 
Em 1906 a Intendência publicou um Edital para realização das obras de saneamento indicadas pelo engenheiro Alfredo Lisboa. ${ }^{15} \mathrm{O}$ conteúdo do Edital sinalizava duas prioridades: a construção de um novo ponto de captação para ampliar a oferta de água em e a construção de uma rede de esgoto.

A Direção da Companhia Hydráulica Pelotense manifestou objeção ao Edital alegando que ele violava o privilégio da exclusividade no abastecimento de água concedido para a empresa pelo governo imperial. Levando o assunto para o âmbito da Justiça, a Companhia pediu a suspensão do Edital. Criou-se assim um atrito entre a municipalidade e Companhia Hydráulica Pelotense. O desfecho deste atrito foi a encampação da empresa, realizada com a mediação do governo estadual e concluída em 30 de novembro de 1908.16

\section{Considerações finais}

O processo de municipalização dos serviços de saneamento nas cidades e Porto Alegre e Pelotas, abordado no decorrer do artigo, não pode ser dissociado da conjuntura econômica e política existente no Rio Grande do Sul da Primeira República. No plano econômico, o período entre 1889 e 1930 foi marcado por um expressivo crescimento na produção agrícola e industrial sul rio-grandense - um crescimento que foi, em parte, fomentado com recursos públicos. No plano político, o PRR fortaleceu-se com a vitória militar obtida na Revolução Federalista de 1893, mas continuou enfrentando grupos de oposição, sobretudo nas cidades da região da Campanha.

Certamente política e economia são coisas distintas, mas também são coisas interdependentes. No caso específico do Rio Grande do Sul na Primeira República, a lógica dessa interdependência era simples: o crescimento econômico ampliava as

\footnotetext{
15 Em 1900 o engenheiro paulista Alfredo Lisboa foi contratado pela Intendência para emitir um parecer técnico sobre as obras de saneamento propostas pelo engenheiro Guilherme Rodolph Ahrons. Lisboa apresentou objeções ao plano de obras proposto por Ahrons e advertiu para a necessidade de ampliar a oferta de água existente na cidade, antes da construção da rede de esgoto. A ampliação poderia ser feita pela Companhia, ou pela própria Intendência, que poderia investir em um novo ponto de captação de água para lavagem dos canos da rede.

16 Para realizar a encampação a municipalidade distribuiu 5.000 apólices de títulos públicos para os acionistas da empresa. Na ocasião da encampação os principais acionistas da Companhia Hydráulica Pelotense eram Joaquim Augusto Assumpção, Pedro da Fontoura Lopes, Vizcondesa da Graça, Maria Jacintha Dias de Campos, Barón y Baronesa de Arroyo Grande, André José de Oliveira, Joaquim da Silva Ferreira, Ildefonso Simões Lopes, Antonio Augusto Assumpção, Francisco Vieira Braga, Luis Carlos de Abreu e Melo e Maria Bernardina Dias da Cunha. Ofício de 28 de dezembro de 1908. (Ficheiro 145 - BPP)
} 


\section{Revista Brasileira de História \& Ciências Sociais - RBHCS}

Vol. $9 \mathrm{~N}^{\mathrm{O}}$ 18, Julho - Dezembro de 2017

possibilidades do PRR manter o seu controle sobre o aparelho político e, no sentido inverso, esse controle possibilitava o gradual fortalecimento do PRR através da ampliação das receitas estaduais, da qualificação dos quadros técnicos e da vitória nas eleições em cidades estratégicas. Dentro desta perspectiva, as duas experiências de municipalização dos serviços de saneamento destacadas no artigo estavam inseridas num processo mais amplo de diversificação da pauta política do PRR e de fortalecimento do partido.

Questões econômicas e políticas foram importantes para viabilizar a municipalização dos serviços de saneamento em Porto Alegre e Pelotas. Essas questões coexistiram com outros fatores contemplados, dentre os quais importa ressaltar a preocupação com a salubridade urbana e a necessidade de imposição das práticas de higiene pública. Como demonstramos no artigo, o Asseio Público realizado por empresas particulares era facultativo e, consequentemente, muitos proprietários de imóveis optavam por evitar o pagamento do serviço descartando as "materias fecaes" em locais inadequados. A resistência da população em aderir ao serviço e a insatisfação com a qualidade do trabalho prestado pelas empresas concessionárias exigiram a intervenção das municipalidades que realizaram as encampações e determinaram a obrigatoriedade da adesão ao Asseio Público para todos os imóveis do perímetro urbano. Neste aspecto, as datas da municipalização foram diferentes (1898 para Porto Alegre e 1904 para Pelotas), mas a lógica do processo foi semelhante.

Sabemos que tanto em Porto Alegre, quanto em Pelotas, quando a República foi implantada, já havia uma expectativa pela construção de redes coletoras de esgoto e o assunto era discutido na imprensa da época. No entanto, as municipalidades não possuíam recursos financeiros para atender essa expectativa, embora ambas estivessem providenciando os estudos técnicos necessários. Nestas condições, a municipalização do Asseio Público, assim como os investimentos na sua expansão e qualificação, foram ações provisórias para atacar um problema que demandava grandes recursos e obras de engenharia complexas.

Uma situação diferente encontramos na municipalização do abastecimento de água. A crescente demanda por água potável e a existência de sistemas de captação e de redes distribuidoras ofereciam uma perspectiva de rápida expansão na oferta do produto e, consequentemente, sinalizavam para a viabilidade financeira de uma 


\section{Revista Brasileira de História \& Ciências Sociais - RBHCS}

Vol. $9 \mathrm{~N}^{\mathrm{O}}$ 18, Julho - Dezembro de 2017

gestão pública do abastecimento de água. Na documentação pesquisada, constatamos que a Intendência de Porto Alegre já possuía planos técnicos e orçamentos para ampliar a oferta de água quando realizou a encampação da Companhia Hydráulica Guahybense, em 1904. Nesta mesma época, a Intendência de Pelotas também já possuía estudos técnicos para ampliar a oferta de água, mas ainda não havia decidido realizar a encampação da Companhia Hydráulica Pelotense. Acreditamos que a ação judicial movida pela empresa contra a municipalidade interferiu nos planos da Intendência e resultou na encampação, acordada em 1908.

$\mathrm{Na}$ condução das negociações com as empresas particulares, as autoridades políticas demonstraram zelo no estudo da viabilidade jurídica, financeira e técnica dos investimentos que resultaram na municipalização do Asseio Público e do abastecimento de água, em Porto Alegre e em Pelotas. Para alguns contemporâneos dos fatos narrados no artigo, esse zelo - manifestado nas prolongadas discussões sobre as prioridades do saneamento registradas na imprensa da época - foi considerado morosidade ou incompetência. Para outros, ele era uma marca positiva na conduta do PRR e uma garantia de que as decisões resultariam em benefícios para a sociedade. Como todos os contemporâneos destes fatos já morreram, para a nossa geração, o mérito da discussão já não interessa. O que importa é a percepção de que as discussões sobre a eficiência das instituições políticas e sobre a transparência dos negócios públicos são antigas e complexas.

\section{Acervos documentais consultados}

Arquivo Histórico de Porto Alegre Moysés Velhinho (AHPAMV).

Arquivo Histórico do Rio Grande do Sul (AHRS).

Biblioteca Pública de Pelotas (BPP).

Biblioteca Nacional do Rio de Janeiro - Hemeroteca Digital (BNRJ-HD).

\section{Referências Bibliográficas}

ARRETCHE, Marta T. S. Estado federativo e políticas sociais: determinantes da descentralização. São Paulo: Revam, 2000.

ASSUMPÇÃO, Jorge Euzébio. Pelotas: Escravidão e Charqueadas. 1780-1888. Porto Alegre: FMC Editora, 2013. 
ÁVILA, Vladimir Ferreira de. Saberes históricos e práticas cotidianas sobre o saneamento: desdobramentos na Porto Alegre do século XIX (1850 - 1900). Dissertação (Mestrado em História) - Programa de Pós-Graduação em História, Pontifícia Universidade Católica do Rio Grande do Sul, Porto Alegre, 2010. <http://repositorio.pucrs.br/dspace/bitstream/10923/3945/1/000425495-

Texto\%2BCompleto-0.pdf >

AXT, Gunter. Gênese do Estado Moderno no Rio Grande do Sul. 1889-1929. Porto Alegre: Editora Paiol, 2011.

CANO, Wilson. Raízes da Concentração Industrial em São Paulo. São Paulo: Hucitec, 1990.

COSTA, Emília Viotti da. Da Senzala à Colônia. $4^{\mathrm{a}}$ edição. São Paulo: UNESP, 1998.

CORBIN, A. Saberes e Odores. São Paulo: Companhia das Letras, 1987.

DACANAL, José H. e GONZAGA, Sergius. RS: Imigração e Colonização. Porto Alegre: Mercado Aberto, 1980.

CARVALHO, José Murilo de. Teatro de sombras: a política imperial. Rio de Janeiro: IUPERJ, 1988.

DEAN, Warren. A industrialização de São Paulo. 2. ed. Rio de Janeiro: Difel, 1976.

FAORO, Raymundo. Os donos do poder: formação do patronato político brasileiro. São Paulo: Globo, 1989, 2 v.

FEE. De Província de São Pedro a Estado do Rio Grande do Sul. Censos do RS: 1803-1950. Porto Alegre: Fundação de Economia e Estatística, 1981.

FERREIRA, Marieta de Moraes. Política e poder no Rio de Janeiro da República Velha. Revista do Rio de Janeiro. Niterói, Vol. 1, n. 1, p. 115-120, set/dez. 1985.

GILL, Lorena. O mal do século: tuberculose, tuberculosos e políticas de saúde pública em Pelotas (RS) 1890-1930. Pelotas: EDUCAT, 2007.

GUTIERRES, Éster J. B. Barro e sangue: mão-de-obra, arquitetura e urbanismo em Pelotas. Tese (Doutorado em História) - Faculdade de Filosofia e Ciências Humanas, Pontifícia Universidade Católica do Rio Grande do Sul, Porto Alegre, 1999.

HUYER, André. A Ferrovia do Riacho. Do sanitarismo a modernização de Porto Alegre. Porto Alegre: EVANGRAF, 2015.

LAPA, José Roberto do Amaral. Economia Cafeeira. São Paulo: Brasiliense, 1986.

LARREA- KILLINGER, Cristina. La Cultura de los Olores: Un aproximación a la antropología de los sentidos. Quito: Ediciones ABYA-YALA, 1997.

LOVE, Joseph. O Regionalismo Gaúcho e as Origens da Revolução de 30. São Paulo: Perspectiva, 1975.

LOVE, Joseph. A locomotiva: São Paulo na federação brasileira, 1889-1937. Rio de Janeiro: Paz e Terra, 1982.

Magalhães, Mário Osório. (Org.). Atas da Câmara Municipal de Pelotas (1832-1845). Santa Maria: Pallotti, 2011. 
PANG, Eul Soo. Coronelismo e oligarquias (1889-1934). A Bahia na Primeira República brasileira. Rio de janeiro: Civilização brasileira, 1979.

PRADO JUNIOR, Caio. Formação do Brasil Contemporâneo: colônia. 12. ed. São Paulo: Brasiliense, 1972.

ROSEN, George. História da saúde pública. São Paulo: Unesp, 2000.

RÜCKERT, Fabiano Quadros. O saneamento e a politização da higiene no Rio Grande do Sul (1828-1930). Tese (Doutorado em História), UNISINOS, São Leopoldo, 2015.

RÜCKERT, Fabiano Quadros. Poder público, imprensa e saneamento na cidade de Pelotas, RS (1834-1908). MOREIRA, Paulo; et al. (Orgs.). Instituições e práticas de controle social: perspectivas de pesquisa. São Leopoldo: OIKOS/Editora UNISINOS, 2016a, p. 317-345.

RÜCKERT, Fabiano Quadros. Porto Alegre e o problema das "materias fecaes": o serviço de Asseio Público e a construção da primeira rede de esgoto na capital do Rio Grande do Sul (1879-1912). Tempos Históricos. Volume 20, $1^{\circ}$ Semestre de 2016b, p. 105-130.

<http://e-revista.unioeste.br/index.php/temposhistoricos/article/view/13551/9953>

SANTOS, Roselys Isabel Correa dos. A terra prometida: emigração italiana: mito e realidade. 2. ed. Itajaí: Editora da UNIVALI, 1999.

SEYFERTH, Giralda. A colonização alemã no Vale do Itajaí-Mirim: um estudo do desenvolvimento econômico. Porto Alegre: Movimento, 1974.

SILVA, Sérgio. Expansão cafeeira e origem da indústria no Brasil. São Paulo: Alfa-Omega, 1976.

SILVEIRA, Aline Montagna da. De fontes e aguadeiros à penas d'água. Reflexões sobre o sistema de abastecimento de água e as transformações da arquitetura residencial no final do século XIX em Pelotas, RS. Tese (Doutorado em Arquitetura) - Programa de Pós-Graduação em Arquitetura e Urbanismo, Universidade de São Paulo, 2009.

SOARES, Paulo Roberto Rodrigues. Del proyecto urbano a la producción del espacio: morfología urbana de la ciudad de Pelotas, Brasil (1812-2000). Tese (Doutorado em Geografia) - Departamento de Geografía Humana, Universidad de Barcelona, Barcelona, 2002.

SOUZA, Donaldo Bello de; FARIA, Lia Ciomar Macedo de. Reforma do Estado, Descentralização e Municipalização do Ensino no Brasil: A Gestão Política dos Sistemas Públicos de Ensino Pós-LDB 9.394/96. Ensaio: aval. pol. públ. Educ., Rio de Janeiro, v.12, n.45, p. 925-944, out./dez. 2004.

URICOCHEA, Fernando. O minotauro imperial. A burocratização do Estado Patrimonial brasileiro no século XIX. Rio de Janeiro/São Paulo: Difel, 1978.

VARGAS, Jonas Moreira. Pelas margens do Atlântico: um estudo sobre elites locais e regionais no Brasil a partir das famílias proprietárias de charqueadas em Pelotas, Rio Grande do Sul (século XIX). Tese (Doutorado em História) - Programa de Pós-Graduação em História, Universidade Federal do Rio de Janeiro, Rio de Janeiro, 2013. 
XAVIER, Janaina Silva. O saneamento em Pelotas (1871-1915): o patrimônio sob o signo de modernidade e progresso. Dissertação (Mestrado em Memória Social e Patrimônio Cultural) - Instituto de Ciências Humanas, Universidade Federal de Pelotas, Pelotas, 2010. < $\underline{\text { http://guaiaca.ufpel.edu.br/bitstream/.../1/Janaina Silva Xavier Dissertacao.pdf }}$ $>$.

VISCARDI, Cláudia. O teatro das oligarquias: uma revisão da "política do café com leite”. Belo Horizonte: Fino Traço, 2012.

ZARTH, Paulo Antônio. Do arcaico ao Moderno: o Rio Grande do Sul agrário do século XIX. Ijuí: Editora UNIJUÍ, 2002.

WEIMER, Günter. A Política Sanitarista como Diretriz de Planejamento na República Velha Gaúcha. In: WEIMER, Günter (Org.). Urbanismo no Rio Grande do Sul. Porto Alegre: UFRGS, p. 93-109, 1992.

WIRTH, John. O fiel da balança: Minas Gerais na federação brasileira (18891937), Rio de Janeiro: Paz e terra, 1982.

Recebido em Junho de 2017 Aprovado em Novembro de 2017

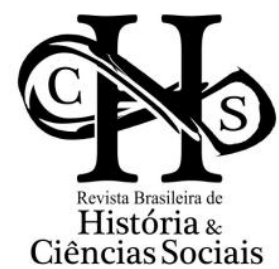

